\title{
Changes in foraminal area with anterior decompression versus keyhole foraminotomy in the cervical spine: a biomechanical investigation
}

\author{
Jacqueline Nguyen, MD, ${ }^{1}$ Bryant Chu, MS, ${ }^{2}$ Calvin C. Kuo, MD, ${ }^{3}$ Jeremi M. Leasure, MS, ${ }^{2}$ \\ Christopher Ames, MD, ${ }^{4}$ and Dimitriy Kondrashov, MD ${ }^{5}$ \\ 1San Francisco Orthopaedic Residency Program; ${ }^{2}$ The Taylor Collaboration, Biomechanics Laboratory, San Francisco; \\ ${ }^{3}$ Department of Spine Surgery, Kaiser Permanente Medical Center, Oakland; ${ }^{4}$ Department of Neurosurgery, University of \\ California, San Francisco Medical Center; and '5epartment of Orthopaedic Surgery, St. Mary's Spine Center, San Francisco, \\ California
}

OBJECTIVE Anterior cervical discectomy and fusion (ACDF) with or without partial uncovertebral joint resection (UVR) and posterior keyhole foraminotomy are established operative procedures to treat cervical disc degeneration and radiculopathy. Studies have demonstrated reliable results with each procedure, but none have compared the change in neuroforaminal area between indirect and direct decompression techniques. The purpose of this study was to determine which cervical decompression method most consistently increases neuroforaminal area and how that area is affected by neck position.

METHODS Eight human cervical functional spinal units (4 each of C5-6 and C6-7) underwent sequential decompression. Each level received the following surgical treatment: bilateral foraminotomy, ACDF, ACDF + partial UVR, and foraminotomy + ACDF. Multidirectional pure moment flexibility testing combined with 3D C-arm imaging was performed after each procedure to measure the minimum cross-sectional area of each foramen in 3 different neck positions: neutral, flexion, and extension.

RESULTS Neuroforaminal area increased significantly with foraminotomy versus intact in all positions. These area measurements did not change in the ACDF group through flexion-extension. A significant decrease in area was observed for ACDF in extension $\left(40 \mathrm{~mm}^{2}\right)$ versus neutral $\left(55 \mathrm{~mm}^{2}\right)$. Foraminotomy + ACDF did not significantly increase area compared with foraminotomy in any position. The UVR procedure did not produce any changes in area through flexionextension.

CONCLUSIONS All procedures increased neuroforaminal area. Foraminotomy and foraminotomy + ACDF produced the greatest increase in area and also maintained the area in extension more than anterior-only procedures. The UVR procedure did not significantly alter the area compared with ACDF alone. With a stable cervical spine, foraminotomy may be preferable to directly decompress the neuroforamen; however, ACDF continues to play an important role for indirect decompression and decompression of more centrally located herniated discs. These findings pertain to bony stenosis of the neuroforamen and may not apply to soft disc herniation. The key points of this study are as follows. Both ACDF and foraminotomy increase the foraminal space. Foraminotomy was most successful in maintaining these increases during neck motion. Partial UVR was not a significant improvement over ACDF alone. Foraminotomy may be more efficient at decompressing the neuroforamen. Results should be taken into consideration only with stable spines.

https://thejns.org/doi/abs/10.3171/2017.2.SPINE141237

KEY WORDS cervical biomechanics; anterior cervical discectomy and fusion; ACDF; foraminotomy; stenosis; foraminal decompression

ABBREVIATIONS ACDF = anterior cervical discectomy and fusion; PLL = posterior longitudinal ligament; UVR = uncovertebral joint resection. ACCOMPANYING EDITORIAL See pp 617-619. DOI: 10.3171/2017.3.SPINE17152.

SUBMITTED December 11, 2014. ACCEPTED February 1, 2017.

INCLUDE WHEN CITING Published online October 13, 2017; DOI: 10.3171/2017.2.SPINE141237. 
$\mathrm{D}$ EGENERATIVE disc disease in the cervical spine can cause neck pain, myelopathy, and/or radiculopathy. Radiculopathy or nerve root compression can be caused by uncinate osteophytes, facet cysts, facet hypertrophy, or disc herniation. To use the old terminology, the exiting cervical nerve can be compressed by a soft disc, hard disc, or a combination thereof. When conservative treatment fails, there are surgical options available that aim to increase the foraminal area to decompress the nerve root and relieve pain, numbness, and/or weakness.

Anterior cervical discectomy and fusion (ACDF) is an established procedure originally described in 1958 by Smith and Robinson. ${ }^{31}$ It has evolved to include a range of different techniques, including direct or indirect decompression of the uncovertebral joint, resection or preservation of posterior longitudinal ligament (PLL), and the use of a graft or cage in the intervertebral disc space. The ACDF procedure is appropriate in the presence of uncovertebral spurs and central disc herniations and is advantageous in that it does not necessarily need to expose the spinal canal. ${ }^{12,33}$ Posterior keyhole foraminotomy (or laminoforaminotomy) offers a less-invasive, motion-sparing alternative to an anterior approach and involves removing part of the superior articular facet to widen the neuroforamen. It is appropriate in patients with posterolateral soft disc herniation or osteophytic spurs originating from the facet joint and is advantageous in that it involves adequate exposure of the nerve root, minimal laminoforaminotomy resection resulting in a limited effect on cervical spine stability, and possibly decreased morbidity and mortality. ${ }^{6,7,12}$ Because it is a motion-preserving procedure, keyhole foraminotomy can possibly have different implications on adjacent-segment disease and the risk of reoperation, although there is no consensus on this topic either in the literature or among expert surgeons.

Both approaches have demonstrated consistent and excellent results. Most studies evaluate only ACDF or foraminotomy. There are only a limited number of studies that directly compare ACDF to foraminotomy, and the majority of these are clinical studies..$^{11,16-18,22,29,35}$ In a biomechanical study, Chen et al. examined the effects of anterior cervical discectomy versus ACDF versus foraminotomy on the stability of the cervical spine; however, to our knowledge there have been no biomechanical studies directly comparing the amount of bony decompression between ACDF and foraminotomy. ${ }^{4-6,8,10,11,13,22,31,33,36}$ Additionally, there are technical details within the ACDF procedure that remain controversial, such as whether to directly resect the posterior part of the uncovertebral joint or its osteophytes and whether to remove the PLL. We aimed to compare ACDF with and without direct posterior uncovertebral joint resection (UVR) with posterior keyhole foraminotomy and to determine which procedure most reliably increased the neuroforaminal area in different neck positions in the cadaveric model.

\section{Methods \\ Study Specimens}

Eight cadaveric cervical functional spinal units (4 each of C5-6 and C6-7) were tested and analyzed. All speci- mens were procured intact and fresh-frozen from national tissue banks. The mean age for all specimens was 73 years. Planar radiographs were taken of each intact spine by using clinical-grade equipment (BV Pulsera, Philips). These images were examined by both the research engineer and a fellowship-trained spine surgeon. Specimens with evidence of prior surgery, tumors, ankylosis, or other bone deformities in the cervical region were excluded from the study. After radiographic examination, the lower cervical spinal section (C4-T2) was isolated. The cranial- and caudal-most vertebrae were cast in shallow cups of quick-set resin (Smooth-Cast 300; Smooth-On) to facilitate loading through a biomechanical test jig (Fig. 1).

\section{Biomechanical Testing}

The biomechanical test apparatus was modeled after a previously validated, nonconstrained, cable-driven, pure moment device. ${ }^{31}$ The specimen was fixed horizontally and subject to pure moment via a fixed ring-pulley system. A winch and turnbuckle were used to generate tension on cables, which was measured in real time by a load cell (JR3) mounted to the test frame (Fig. 1). To ensure minimal imaging interference, all parts of the frame directly in line with imaging trajectories were fabricated from radiolucent polymer. In the intact state and after each surgical procedure, each specimen was imaged in flexion/ extension at $1.5 \mathrm{Nm}$ and in the neutral position at $0 \mathrm{Nm}$. These loads are consistent with prior biomechanical tests of the cervical spine by our group ${ }^{25,27,32}$ and others ${ }^{1,9,23,24,28}$, 31,32 and are safely within the nondestructive range.

\section{Surgical Preparation}

All functional spinal units underwent sequential decompressions. Each level was randomly assigned to one of two surgical sequences. One sequence consisted of bilateral foraminotomy, ACDF, and ACDF + partial UVR. The other sequence consisted of ACDF and ACDF + UVR (spines did not receive the initial foraminotomy). Our total number of surgical treatment groups was 6: 1) intact; 2) ACDF; 3) foraminotomy; 4) ACDF + UVR; 5) ACDF + foraminotomy; and 6) ACDF + UVR + foraminotomy. The sample size was 16 for the intact group and 8 for all other groups. A 3D Carm imaging unit (BV Pulsera, Philips) was used to confirm the correct vertebral level and preoperative disc height.

Direct decompressions via keyhole foraminotomy were performed according to the following procedure. The posterior musculature was dissected to expose the lamina and facet joints bilaterally, with care taken to preserve the facet capsules. An interlaminar "V" was identified, and a highspeed bur was used to resect the overlying inferior articular facet to the lateral margin of each pedicle. Once the superior articulating facet was exposed, it was also resected to the lateral margin of each pedicle. The overall area of foraminotomy was approximately $5-7 \mathrm{~mm}$ in diameter. Special attention was given by means of direct visualization to resect no more than $50 \%$ of each facet joint. A nerve hook was used to palpate the lateral aspect of the cranial and caudal pedicles to ensure adequate decompression. ${ }^{34}$

The ACDF was performed as follows. The exposed 


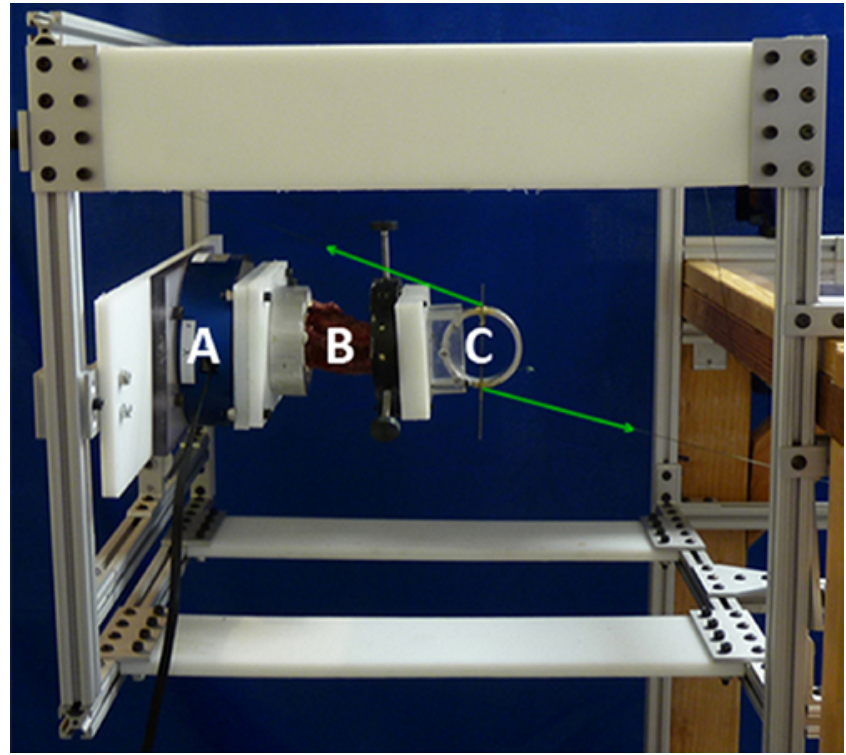

FIG. 1. Biomechanical test jig to reproduce anatomical postures (neutral, flexion, extension). A: Load cell. B: Specimen. C: Pure moment fixture. Green arrows represent the coupled tensile forces applied to the uppermost vertebrae. Figure is available in color online only.

disc was incised and removed until the PLL and uncinate processes were visualized. A high-speed bur was used to remove cartilaginous endplates down to the bony endplate, as well as to remove anterior and posterior osteophytes. The specimen was placed in lordosis with the use of a laminar spreader to distract the disc space. A fibular strut allograft $6 \mathrm{~mm}$ in height with parallel ends was inserted into the disc space approximately $2 \mathrm{~mm}$ posterior to the anterior edge of the endplates. A 6-mm allograft was chosen to standardize the size of the graft used for all cadaver specimens, based on our preoperative assessment of native disc height. A 6-hole plate with 6 variable-angle screws (Synthes Spine) was placed anteriorly to stabilize both levels.

Partial UVR was performed according to the following procedure. The anterior plate and screws were removed, as well as the fibular allograft. The PLL was then incised and resected, and the posterior one-third of the uncinate process (approximately $3 \mathrm{~mm}$ ) and uncinate spurs (if any) were removed on each side to decompress both neuroforamina. When a nerve hook could be passed easily into the foramen anterior to the exiting nerve root, the posterior UVR was considered complete. The same fibular 6-mm allografts and 6-hole anterior plate with unicortical vertebral body screws were placed. ${ }^{34}$

\section{Data Collection and Processing}

The 3D radiographic sequences of each specimen were acquired in each anatomical posture (neutral, flexion, and extension) by a 3D C-arm imaging unit at a resolution of $0.7 \times 0.7 \times 0.7 \mathrm{~mm}$. Images were then imported into medical image processing software (Mimics 15, Materialise). The neuroforamina of interest (left and right at C5-6 and C6-7) were isolated and recreated as 3D solid models (Fig. 2) by using previously validated segmentation tech-

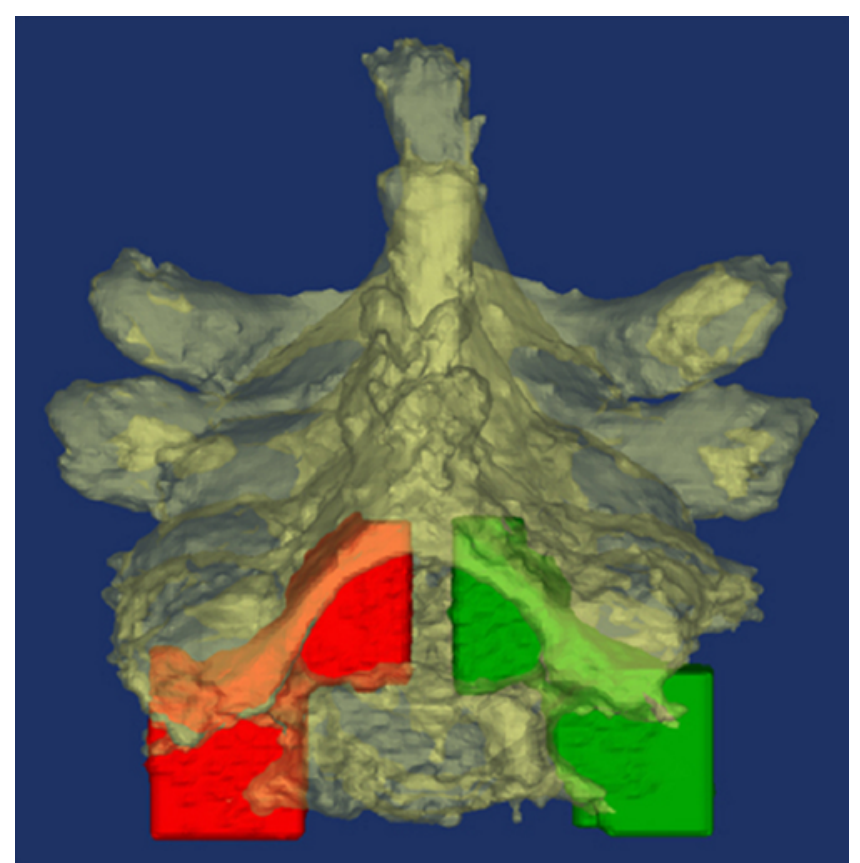

FIG. 2. A 3D model of the right (red) and left (green) foramina for 1 level. Figure is available in color online only.

niques. ${ }^{37}$ The cross-sectional area orthogonal to each foraminal trajectory was recorded at 1-mm-slice-thickness intervals. The minimum cross-sectional area of each foramen was then extracted as the primary outcome measure for analysis. This image processing technique has been validated with an accuracy of $3.9 \%$ and repeatability of $1.6 \%$ in quantifying foraminal area.

\section{Data Analysis}

The primary outcome measure was the minimum cross-sectional area in all 3 positions (neutral, flexion, and extension). This outcome was assessed at both C5-6 and $\mathrm{C6}-7$ for all treatment groups, with each foramen as its own control. One-way ANOVA was performed to determine any significant differences between treatment groups for each of 3 tested postures.

\section{Results}

In the neutral neck position, the average neuroforaminal area for the intact specimens before any procedures had been performed was $46.3 \pm 11.0 \mathrm{~mm}^{2}$, and the average disc height for all specimens was $4.40 \pm 0.89 \mathrm{~mm}$ (range $3.16 \mathrm{~mm}-5.83 \mathrm{~mm}$ ). After ACDF, the average area increased to $51.1 \pm 10.1 \mathrm{~mm}^{2}$, and after the addition of posterior UVR, the average area was found to be $48.2 \pm$ $6.7 \mathrm{~mm}^{2}$. After foraminotomy, the average area increased to $68.6 \pm 12.9 \mathrm{~mm}^{2}$, which was statistically significant $(\mathrm{p}$ $<0.05$ ) when compared with the area of the intact specimens. The combination of ACDF + foraminotomy and $\mathrm{ACDF}+\mathrm{UVR}+$ foraminotomy resulted in average areas of $68.1 \pm 15.0 \mathrm{~mm}^{2}$ and $71.1 \pm 13.1 \mathrm{~mm}^{2}$, respectively, both of which resulted in a significantly greater area than in intact specimens (Fig. 3). 


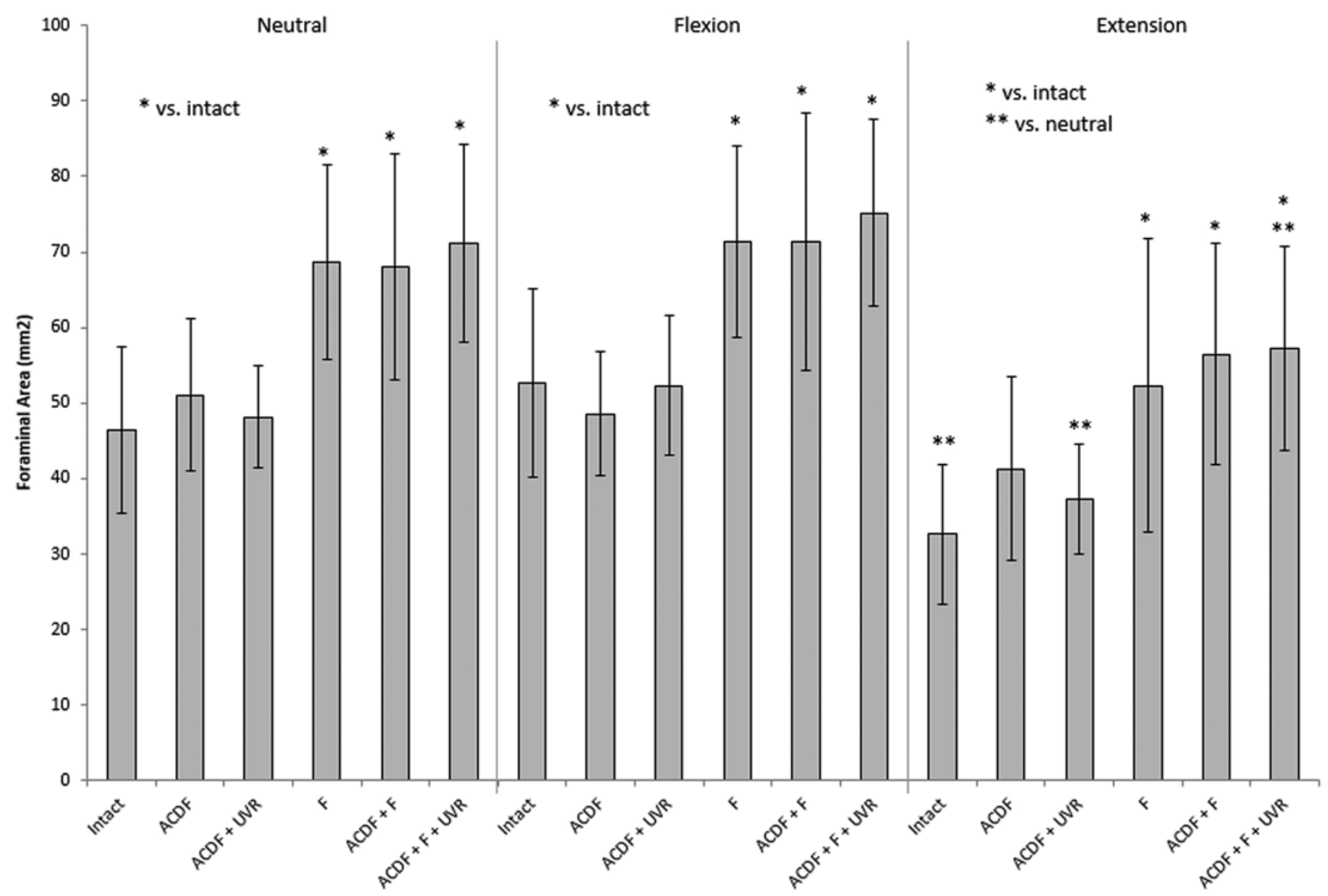

FIG. 3. Bar graph showing comparisons of 6 treatment groups in 3 loading conditions. Asterisks represent statistically significant differences.

In flexion, the intact specimens had an average neuroforaminal area of $52.7 \pm 12.4 \mathrm{~mm}^{2}$, and after ACDF without and then with UVR, the areas were found to be $48.6 \pm 8.3$ $\mathrm{mm}^{2}$ and $52.3 \pm 9.2 \mathrm{~mm}^{2}$, respectively. After foraminotomy, the average area increased a significant amount, to 71.5 $\pm 12.7 \mathrm{~mm}^{2}$ when compared with the intact specimens in the flexed position. When ACDF + foraminotomy was performed, the average area increased to $71.4 \pm 17.1 \mathrm{~mm}^{2}$, and when ACDF was combined with UVR and foraminotomy (i.e., ACDF + UVR + foraminotomy), the average area was $75.1 \pm 12.4 \mathrm{~mm}^{2}$, both of which were significant (Fig. 3).

In extension, the intact specimens had an average area of $32.7 \pm 9.3 \mathrm{~mm}^{2}$, which was a significant decrease in area when compared with the same intact specimens in the neutral neck position. After ACDF, the area was an average of $41.3 \pm 12.1 \mathrm{~mm}^{2}$. With the addition of UVR to ACDF (i.e., ACDF + UVR), the area was significantly decreased $\left(37.3 \pm 7.2 \mathrm{~mm}^{2}\right)$ when compared with the same specimens in the neutral position. After foraminotomy alone and ACDF + foraminotomy, the average areas were found to be $52.3 \pm 19.4 \mathrm{~mm}^{2}$ and $56.5 \pm 14.6 \mathrm{~mm}^{2}$, respectively, both of which were significant increases when compared with intact specimens in extension. After ACDF + UVR + foraminotomy, the average area was $57.2 \pm 13.6$ $\mathrm{mm}^{2}$, which was a significant increase when compared with intact specimens in extension but a significant decrease when compared with the same specimens in the neutral neck position (Fig. 3).

\section{Discussion}

Excellent clinical results have been demonstrated with posterior keyhole foraminotomy and ACDF for the treatment of cervical radiculopathy. In a direct prospective comparison between anterior and posterior approaches for the treatment of disc herniations, Herkowitz et al. demonstrated no statistically significant clinical difference between the 2 procedures; they both yielded good results. ${ }^{11}$ Selvanathan et al. compared the effectiveness of ACDF to foraminotomy with validated outcome measures and found that both procedures demonstrated similar clinical improvements. ${ }^{29}$ Furthermore, a recent systematic review determined that there were no differences between ACDF and foraminotomy with respect to clinical outcomes, complication rates, or reoperation rates. ${ }^{17}$ Additionally, a cost analysis study by Mansfield et al. found that on average ACDF costs $89 \%$ more than foraminotomy-due mostly to the use of implants-suggesting that surgeons should consider posterior foraminotomy for the treatment of cervical radiculopathy. ${ }^{19}$ 
This is the first biomechanical cadaveric study to directly compare the changes in neuroforaminal area between the 2 procedures. ${ }^{4,5,8,10,13,31,33,36}$ Previous analyses of in vitro and in vivo changes in the cervical foramen with different neck positions have demonstrated that flexion increases foraminal area. Extension of the neck decreases the area, thus contributing to further compression of the exiting nerve root and an exacerbation of symptoms in extension (Spurling sign). ${ }^{2,15,20,21}$ Our data from cadaveric specimens support these findings; flexion increased the area but not to a significant degree, whereas extension significantly decreased the neuroforaminal area by an average of $29.6 \%$ (average of $46.4 \mathrm{~mm}^{2}$ in intact neutral to 32.7 $\mathrm{mm}^{2}$ in intact extension).

We do believe that for some scenarios all 3 procedures can be applied (for instance, foraminal stenosis due to an uncovertebral spur), whereas for other situations some procedures might be not indicated (for example, soft disc herniation in a more central location that is inaccessible from the back).

Although all procedures-including ACDF, ACDF + UVR, and foraminotomy-increased the neuroforaminal area, foraminotomy increased the area to the greatest extent and the most consistently, because it widened the area to a significant degree in all 3 neck positions. In our cadaveric specimens, foraminotomy increased the area in neutral by $48.0 \%$, in flexion by $35.7 \%$, and in extension by $60.2 \%$. Most importantly, this increase in area seen in foraminotomy, as well as foraminotomy + ACDF, was maintained in extension - the position where symptoms are the most severe; there was not a statistically significant decrease in the area when compared with foraminotomy in the neutral position. This also indicates that it is not a destabilizing procedure for the cervical spine. These findings support the study done by Chen et al., who reported that posterior foraminotomy had little effect on the stability of the cervical motion segment when less than $50 \%$ of the facet joints were resected. ${ }^{6}$

Previous literature clearly shows that ACDF produces excellent clinical results, but there is no clear understanding as to which aspect of the procedure contributes most to pain relief. In their review of 18 patients who had undergone ACDF, Albert et al. revealed that there was no significant correlation between graft height and the change in maximum foraminal area and postoperative relief of symptoms. ${ }^{2}$ They concluded that indirect decompression by means of disc space distraction may not be the primary contributor to the clinical success of ACDF. Our results are consistent with this finding because, although ACDF increased the neuroforaminal area in all 3 neck positions, it was not by a significant amount. In the neutral position, ACDF only increased the area by $10.1 \%$. This would lead one to believe that it may be the direct decompression that is largely responsible for the pain relief.

Shen at al. ${ }^{30}$ compared 2 patient groups that had either ACDF with indirect decompression by disc space distraction or direct posterior uncovertebral joint decompression. They have found that the patients who had direct UVR had no significant differences in outcomes when compared with the indirect decompression group. Both study groups had good clinical results. These investigators concluded that direct partial UVR was not necessary and only exposed the patient to further risks. ${ }^{30}$ Our results support this finding as well; we found that not only did the addition of the posterior UVR fail to increase the area, it also contributed to destabilizing the spinal unit (the area in extension significantly decreased when compared with ACDF + UVR in the neutral neck position) - a finding that has also been established in previous studies. ${ }^{14}$ Although posterior UVR did not increase the area any further, partial resection of this joint can still be important for removal of soft disc herniations.

Thus, if both the direct partial UVR and indirect decompression by disc space distraction do not significantly increase the neuroforaminal area in ACDF, it is possible that not much of an increase in foraminal area is needed for pain relief. Some believe that radiculopathic pain is actually the result of compressing the relatively small radicular artery. Additionally, it may be the stabilization of the spinal unit by means of fusion and instrumentation, with resultant elimination of pathological motion of the uncovertebral spurs, that is an important aspect of the ACDF. Previous literature has also described how mechanical compression of a nerve can cause venous obstruction in the foramen and decreased blood supply to the nerve, leading ultimately to pain.,26 Therefore, another potential contributing factor is the improvement in the vascular supply to the exiting nerve root, with subsequent relief of ischemic pain.

\section{Limitations of the Study}

There are potential limitations to our study. First, we have a relatively small sample size of 8 motion segments. A power analysis of these comparisons revealed that 6 of our 12 statistically significant comparisons produced statistical power greater than $80 \%$, indicating sufficient sample size. Three of the remaining 6 comparisons produced statistical power greater than $75 \%$, leaving 3 comparisons between $47 \%$ and $53 \%$. Our comparison with perhaps the strongest clinical implication was ACDF + UVR in the neutral position versus extension position, which produced a statistical power of exactly $80 \%$. Although these power analyses should be taken into consideration during the interpretation of the results presented in this study, we believe that the trends observed between direct and indirect decompression and their effect on the clinical implications of this work remain clear and evident.

A second limitation of our study is the decision to investigate the C5-6 and C6-7 levels. Our study may not be generalizable to the rest of the subaxial cervical spine because we have only analyzed C5-7. We do not believe that C3-5 and C7-T1 would show different results; however, this would need to be addressed by future studies. Also, some practitioners do not decompress the C5 nerve root posteriorly out of fear of C5 palsy. Thus, our findings are less applicable to the C4-5 level, because most patients will get an ACDF surgery for this particular level.

A third limitation of our study relates to the standardization of graft size. A 6-mm graft was chosen for all intervertebral disc spaces to standardize the graft height. A previous study by An et al. determined that for a preoperative disc height of $3.5-6.0 \mathrm{~mm}$, a graft size $2-3 \mathrm{~mm}$ 
greater than baseline was appropriate because it resulted in the maximum incremental increase in foraminal height and area. ${ }^{3}$ The average preoperative disc height in our specimens was $4.40 \pm 0.89 \mathrm{~mm}$, with a range between $3.16 \mathrm{~mm}$ and $5.83 \mathrm{~mm}$. None of our specimens exhibited disc heights larger than $6 \mathrm{~mm}$; therefore, all specimens received some amount of distraction. Six of our 8 specimens exhibited disc heights that were appropriate to receive the 6-mm graft size. Only 2 of our specimens exhibited disc heights that may have been more appropriate to receive a 7-mm graft.

Fourth, the average specimen age in our study was 73 years, which is somewhat older than the average age for a typical patient undergoing ACDF. This limits the generalizability of our study across all age groups. New studies including younger cadavers with possibly less spondylosis and greater bone density are being planned.

Last, our specimens did not necessarily have any pathological conditions that would have resulted in radiculopathy in "real life." Therefore, it is possible that in real patients only a small increase in the foraminal area is needed for clinical improvement (for instance, in cases of soft disc herniations). Despite these shortcomings, our study is the first one to directly compare the change in neuroforaminal area between posterior foraminotomy and ACDF with or without UVR.

\section{Conclusions}

Posterior keyhole foraminotomy and ACDF with or without posterior UVR can both be used to treat cervical radiculopathy. Keyhole foraminotomy is particularly useful for facet joint hypertrophy or posterolateral disc herniations, whereas ACDF has an important role in central disc herniations. Yet, when deciding between the 2 procedures, such as in cases of lateral disc herniation or foraminal stenosis, the surgeon may consider a foraminotomy over ACDF, because our study demonstrated that this procedure produced the greatest increase in area in all 3 neck positions and that this area was maintained in extension. Foraminotomy may also be considered as a salvage procedure in patients with persistent radiculopathy after a prior ACDF. Additionally, although partial UVR in ACDF did not demonstrate any increase in area, it can still have a role in removal of soft disc herniations. Our findings pertain primarily to bony stenosis and may not apply to soft disc pathology.

\section{Acknowledgments}

A grant of CHF 49,387 (Swiss francs; US \$49,760) was provided by the AO Foundation to The Taylor Collaboration.

\section{References}

1. Adams MS, Crawford NR, Chamberlain RH, Sonntag VKH, Dickman CA: Biomechanical comparison of anterior cervical plating and combined anterior/lateral mass plating. Spine J 1:166-170, 2001

2. Albert TJ, Smith MD, Bressler E, Johnson LJ: An in vivo analysis of the dimensional changes of the neuroforamen after anterior cervical diskectomy and fusion: a radiologic investigation. J Spinal Disord 10:229-233, 1997

3. An HS, Evanich CJ, Nowicki BH, Haughton VM: Ideal thickness of Smith-Robinson graft for anterior cervical fusion.
A cadaveric study with computed tomographic correlation. Spine (Phila Pa 1976) 18:2043-2047, 1993

4. Bailey RW, Badgley CE: Stabilization of the cervical spine by anterior fusion. J Bone Joint Surg Am 42-A:565-594, 1960

5. Cağlar YS, Bozkurt M, Kahilogullari G, Tuna H, Bakir A, Torun F, et al: Keyhole approach for posterior cervical discectomy: experience on 84 patients. Minim Invasive Neurosurg 50:7-11, 2007

6. Chen BH, Natarajan RN, An HS, Andersson GB: Comparison of biomechanical response to surgical procedures used for cervical radiculopathy: posterior keyhole foraminotomy versus anterior foraminotomy and discectomy versus anterior discectomy with fusion. J Spinal Disord 14:17-20, 2001

7. Epstein NE: A review of laminoforaminotomy for the management of lateral and foraminal cervical disc herniations or spurs. Surg Neurol 57:226-234, 2002

8. Gore DR, Sepic SB: Anterior cervical fusion for degenerated or protruded discs. A review of one hundred forty-six patients. Spine (Phila Pa 1976) 9:667-671, 1984

9. Greene DL, Crawford NR, Chamberlain RH, Park SC, Crandall D: Biomechanical comparison of cervical interbody cage versus structural bone graft. Spine J 3:262-269, 2003

10. Henderson CM, Hennessy RG, Shuey HM Jr, Shackelford EG: Posterior-lateral foraminotomy as an exclusive operative technique for cervical radiculopathy: a review of 846 consecutively operated cases. Neurosurgery 13:504-512, 1983

11. Herkowitz HN, Kurz LT, Overholt DP: Surgical management of cervical soft disc herniation. A comparison between the anterior and posterior approach. Spine (Phila Pa 1976) 15:1026-1030, 1990

12. Hsu WK: Advanced techniques in cervical spine surgery. J Bone Joint Surg Am 93:780-788, 2011

13. Jacobs W, Willems PC, Kruyt M, van Limbeek J, Anderson PG, Pavlov P, et al: Systematic review of anterior interbody fusion techniques for single- and double-level cervical degenerative disc disease. Spine (Phila Pa 1976) 36:E950-E960, 2011

14. Jayson MI: The role of vascular damage and fibrosis in the pathogenesis of nerve root damage. Clin Orthop Relat Res (279):40-48, 1992

15. Kitagawa T, Fujiwara A, Kobayashi N, Saiki K, Tamai K, Saotome K: Morphologic changes in the cervical neural foramen due to flexion and extension: in vivo imaging study. Spine (Phila Pa 1976) 29:2821-2825, 2004

16. Korinth MC, Krüger A, Oertel MF, Gilsbach JM: Posterior foraminotomy or anterior discectomy with polymethyl methacrylate interbody stabilization for cervical soft disc disease: results in 292 patients with monoradiculopathy. Spine (Phila Pa 1976) 31:1207-1216, 2006

17. Liu WJ, Hu L, Chou PH, Wang JW, Kan WS: Comparison of anterior cervical discectomy and fusion versus posterior cervical foraminotomy in the treatment of cervical radiculopathy: a systematic review. Orthop Surg 8:425-431, 2016

18. Lubelski D, Healy AT, Silverstein MP, Abdullah KG, Thompson NR, Riew KD, et al: Reoperation rates after anterior cervical discectomy and fusion versus posterior cervical foraminotomy: a propensity-matched analysis. Spine J 15:1277-1283, 2015

19. Mansfield HE, Canar WJ, Gerard CS, O'Toole JE: Single-level anterior cervical discectomy and fusion versus minimally invasive posterior cervical foraminotomy for patients with cervical radiculopathy: a cost analysis. Neurosurg Focus 37(5):E9, 2014

20. Muhle C, Resnick D, Ahn JM, Südmeyer M, Heller M: In vivo changes in the neuroforaminal size at flexion-extension and axial rotation of the cervical spine in healthy persons examined using kinematic magnetic resonance imaging. Spine (Phila Pa 1976) 26:E287-E293, 2001 
21. Nuckley DJ, Konodi MA, Raynak GC, Ching RP, Mirza SK: Neural space integrity of the lower cervical spine: effect of normal range of motion. Spine (Phila Pa 1976) 27:587-595, 2002

22. Onimus M, Destrumelle N, Gangloff S: [Surgical treatment of cervical disk displacement. Anterior or posterior approach?] Rev Chir Orthop Reparatrice Appar Mot 81:296-301, 1995 (Fr)

23. Phillips FM, Tzermiadianos MN, Voronov LI, Havey RM, Carandang G, Dooris A, et al: Effect of two-level total disc replacement on cervical spine kinematics. Spine (Phila Pa 1976) 34:E794-E799, 2009

24. Porter RW, Crawford NR, Chamberlain RH, Park SC, Detwiler PW, Apostolides PJ, et al: Biomechanical analysis of multilevel cervical corpectomy and plate constructs. J Neurosurg 99 (1 Suppl):98-103, 2003

25. Rodriguez JP, Scheer J, Eguizabal J, Buckley JM, Deviren $\mathrm{V}$, McClellan T, et al: Cervical posterior fusion rods undergo substantial bending deformations for activities of daily living. Spine J 10 (9 Suppl):S81, 2010

26. Rydevik B, Brown MD, Lundborg G: Pathoanatomy and pathophysiology of nerve root compression. Spine (Phila Pa 1976) 9:7-15, 1984

27. Scheer JK, Tang JA, Deviren V, Acosta F, Buckley JM, Pekmezci M, et al: Biomechanical analysis of cervicothoracic junction osteotomy in cadaveric model of ankylosing spondylitis: effect of rod material and diameter. J Neurosurg Spine 14:330-335, 2011

28. Scheer JK, Tang J, Eguizabal J, Farin A, Buckley JM, Deviren V, et al: Optimal reconstruction technique after C-2 corpectomy and spondylectomy: a biomechanical analysis. J Neurosurg Spine 12:517-524, 2010

29. Selvanathan SK, Beagrie C, Thomson S, Corns R, Deniz K, Derham C, et al: Anterior cervical discectomy and fusion versus posterior cervical foraminotomy in the treatment of brachialgia: the Leeds spinal unit experience (2008-2013). Acta Neurochir (Wien) 157:1595-1600, 2015

30. Shen FH, Samartzis D, Khanna N, Goldberg EJ, An HS: Comparison of clinical and radiographic outcome in instrumented anterior cervical discectomy and fusion with or without direct uncovertebral joint decompression. Spine J 4:629-635, 2004

31. Smith GW, Robinson RA: The treatment of certain cervicalspine disorders by anterior removal of the intervertebral disc and interbody fusion. J Bone Joint Surg Am 40-A:607-624, 1958

32. Snyder JT, Tzermiadianos MN, Ghanayem AJ, Voronov LI,
Rinella A, Dooris A, et al: Effect of uncovertebral joint excision on the motion response of the cervical spine after total disc replacement. Spine (Phila Pa 1976) 32:2965-2969, 2007

33. van Limbeek J, Jacobs WCH, Anderson PG, Pavlov PW: A systematic literature review to identify the best method for a single level anterior cervical interbody fusion. Eur Spine J 9:129-136, 2000

34. Wiesel SW (ed): Operative Techniques in Orthopaedic Surgery. Philadelphia: Lippincott, Williams \& Wilkins, 2010, pp 4543-4553, 4562-4567, 2010

35. Wirth FP, Dowd GC, Sanders HF, Wirth C: Cervical discectomy. A prospective analysis of three operative techniques. Surg Neurol 53:340-348, 2000

36. Witzmann A, Hejazi N, Krasznai L: Posterior cervical foraminotomy. A follow-up study of 67 surgically treated patients with compressive radiculopathy. Neurosurg Rev 23:213-217, 2000

37. Yoo JU, Zou D, Edwards WT, Bayley J, Yuan HA: Effect of cervical spine motion on the neuroforaminal dimensions of human cervical spine. Spine (Phila Pa 1976) 17:1131-1136, 1992

\section{Disclosures}

Dr. Ames reports being a consultant for Stryker, DePuy, and Medtronic; receiving royalties from Aesculap and Biomet Spine; owning stock and/or stock options in Baxano and Doctors Research Group; and being an employee of the University of California, San Francisco.

\section{Author Contributions}

Conception and design: Leasure, Ames, Kondrashov. Acquisition of data: Leasure, Nguyen, Chu, Kuo, Kondrashov. Analysis and interpretation of data: all authors. Drafting the article: all authors. Critically revising the article: Leasure, Nguyen, Kuo, Ames, Kondrashov. Reviewed submitted version of manuscript: all authors. Statistical analysis: Leasure, Chu, Kondrashov. Administrative/ technical/material support: Leasure, Ames, Kondrashov. Study supervision: Leasure, Ames, Kondrashov.

\section{Correspondence}

Jeremi Leasure, The Taylor Collaboration, 450 Stanyan St., San Francisco, CA 94117. email: j.leasure@taylorcollaboration.org. 